\title{
Peri-Implant Health and Peri-implant Bone Stability after Immediate Implant Placement
}

\author{
Henriette Lerner ${ }^{1,2 *}$, Jonas Lorenz ${ }^{1}$, Robert A Sader ${ }^{1}$ and Shahram Ghanaati ${ }^{1}$ \\ ${ }^{1}$ Department for Oral, Cranio Maxillo facial and Facial Plastic Surgery, Medical Center of the Goethe University, Germany \\ ${ }^{2}$ HL Dent clinic, Germany
}

*Corresponding author: Henriette Lerner, Director of HL Dent clinic, Department for Oral, Cranio Maxillo facial and Facial Plastic Surgery, Medical Center of the Goethe University, Baden-Baden, Germany

Submission: 㭰 March 05, 2018; Published: 眥 August 07, 2018

\begin{abstract}
Dental implants have become a reliable and predictable treatment modality to replace missing teeth and retain dentures in edentulous patients. They can restore the oral health, form, function, mastication, articulation and aesthetics of the stomatognathic system with multiyear success rates of more than 90 percent for implants in fully edentulous [1,2] or partially edentulous patients [3-6]. Variations in implant success have been found dependent upon surgical technique, loading protocol, implant localisation and bone quality for example, lower success rates have been reported for maxillary implants than for mandibular implants $[7,8]$.
\end{abstract}

\section{Introduction}

In the past few decades, research on dental implants has led to a broad modification of the surgical and prosthetic protocols. The original protocol of submerged healing with complete mucosal coverage during the osseointegration phase isolated dental implants from the oral cavity, avoiding trauma and infection and established favourable conditions for uneventful initial healing [9]. In addition to submerged healing, further surgical and prosthetic protocols such as transgingival healing, immediate implant placement and immediate loading of dental implants have been shown to provide stable clinical and aesthetic long term results [10-14].

The ultimate aim of implant placement, especially, but not only, in cases of tooth loss in the aesthetic zone, is the preservation of hard and soft tissue after tooth loss to restore function and aesthetics. Different techniques have been proposed for preserving the morphology of the alveolar ridge $[15,16]$, including guided bone regeneration [17], socket preservation [18-20], immediate implant placement [21-24] and different combinations of these options $[15,25]$. Maintaining the hard and soft tissue is a primary condition for highly aesthetic results, particularly in the aesthetic zone. The extraction of an anterior tooth typically results in the loss of hard and soft tissue volume, especially in the fragile buccal bone. To compensate for these changes, which might compromise the aesthetic results of a prosthetic rehabilitation, immediate implant placement in combination with minimally invasive extraction techniques have been established in the past few years [26]. Beside anatomical considerations, such as the bone and soft tissue volume and quality, an implant system that meets specific technical and constructional demands is required for long term implant success [27]. The inte gration of material, physical, chemical, mechanical, biological and technical factors ensures the osseointegration of dental implants and long-lasting anchorage in the peri implant bone [27]. Currently, numerous implant systems are available, in a range of sizes, shapes, coatings and prosthetic components [28].

For the surface of dental implants there is a clear consensus regarding the superiority of roughened/ micro textured surfaces compared to machined surfaces to maximize the implant/bone contact area. In vivo and clinical studies have demonstrated that there is significantly greater bone apposition and integration when using implants with micro textured surfaces [29]. Other ways to increase the implant surface include the thread design, implant length and implant diameter. The implant design should incorporate features that best transform tensile and shear forces during mastication and minimize undesirable force components [30].

Also essential for the long term stability of peri implant bone tissue and an aesthetically and functionally sufficient dental implant is the stability of the implant/abutment connection, to prevent implant fractures and screw loosening and to keep the peri implant bone level stable [31-33]. A space or micro gap between the implant and abutment is unavoidable with a two piece design; however, a smaller micro gap can also sometimes be found in designs with platform switching and Morse tapered conical connectors, used to transfer the micro gap facing the implant axis and reduce micro movement. This can reduce the propulsion of sulcus fluid and, consequently, crestal bone loss, even with implants inserted below the alveolar crest (sub-crestally) $[34,35]$. The aim of the present retrospective study was to describe the clinical and radiological results 
of a new implant system with a grit blasted and acid etched surface topography and a Morse locking conical implant/abutment connection. Implants were inserted in fresh and intact extraction sockets of maxillary and mandibular non-salvageable teeth and were followed up clinically and radio logically after a mean loading time of two years. Special emphasis was placed on the maintenance of per implant health and the stability of per implant bone level.

\section{Materials and Methods}

\section{Study design and patient population}

The present retrospective study reports clinical and radiological results for 50 dental implants (C-Tech Implants Esthetic Line; C-Tech Implants, Bologna, Italy) placed immediately after the extraction of non3 salvageable teeth in 21 patients (eleven women ten men) at the HL Dent clinic in Baden-Baden, Germany. The study was approved by the ethics committee of the medical department of the Goethe University, Frankfurt am Main, Germany. Patients presented prior to implant placement with non-salvageable maxillary and mandibular teeth. Implants were placed immediately after tooth extraction in case of an intact alveolar socket in the upper (31 implants) and lower (19 implants) jaw. A total of ten implants, all in the upper molar region, were loaded immediately, while $40 \mathrm{im}$ plants were restored after a mean period of osseointegration of six months after placement. In total, 44 implants were restored with fixed and six implants with removable prosthetics. After a mean loading period of two years, the implants were examined regarding implant survival, implant success and marginal bone loss. In some patients, further implants were placed using a delayed protocol after tooth loss; these implants were not included in the follow up study.

\section{C-Tech implant system}

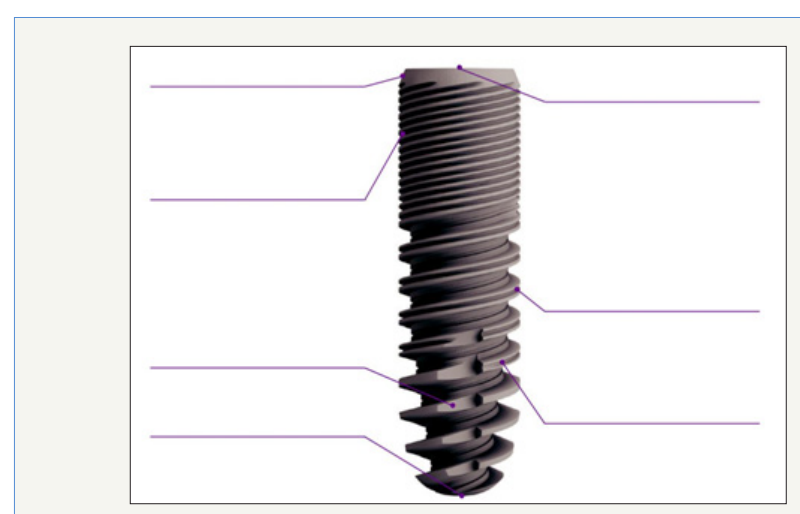

Figure 1:

In the present retrospective study, dental implants of the Esthetic Line (EL; C-Tech Implants, Bologna, Italy) were placed. The implant system combines several design features proven to guarantee long-term stability, peri-implant health and ease of handling. The bone-level implants allow equicrestal or sub-crestal placement and prevent implant exposure through bone re-sorption, which makes them ideal for the aesthetic zone. Implants are manufactured with three different threading profiles, adapted to different bone structures along the depth of the implant, and guarantee high levels of primary stability. Further, they have a bevelled shoulder, which facilitates bone growth above the shoulder, and a grit blasted and acid etched surface topography. The implant provides a Morse locking conical connection with platform switching and an indexing hex. Peri implant bone loss is prevented and the biologic width can be preserved. Figure 1 is a schematic representation of the C-Tech implant system with the main construction characteristics.

\section{Surgical procedure}

Immediate implant placement was considered in case of teeth not worth preserving that were free of acute infections, with stable extraction sockets and sufficient bone quality and quantity to achieve a sufficient rate of primary stability. In all patients, implant placement and previous tooth extraction was performed under local anaesthesia (Figure 1). After tooth extraction, a mini-malinvasive muco periosteal flap without releasing incisions was mobilized for a better overview of the extraction site. Thereby, particular attention was paid to the buccal bone. In the upper incisor region, the implant position was set slightly palatally in relation to the extracted teeth. Subsequently, implant bed preparation was performed according to the surgical protocol of the C-Tech implant system. The number, positions, lengths and diameters of the implants were planned by clinical examination, analysis of jaw models and two or three dimensional radiographs (cone beam computed tomography or panoramic radiographs). Implants were placed sub-crestally with an insertion torque of at least $25 \mathrm{Ncm}$. A sealing screw was incorporated, and wound margins were adapted with absorbable tension free single sutures.

In the case of delayed loading, implants were uncovered after a mean healing period of six months (four to seven months). In total, 44 implants were restored with fixed dentures and 6 with removable dentures. Medication after implant placement consisted of a chlorhexidine 0.2 percent mouth rinse and ibuprofen $400 \mathrm{mg}$. In patients with more than two implants or in combination with further augmentation procedures, additional antibiotics (Augmentin) were prescribed for five days. Table 1 gives an overview of retrospectively investigated implants with implant localisation, implant data, immediately or delayed loading, and prosthetic rehabilitation.

\section{Clinical follow-up}

Two years after implant insertion, a clinical and radiological follow-up was conducted at HL Dent clinic, Baden-Baden, Germany, using previously published methods [36,37]. The following parameters were examined: implant survival, width and thickness of peri implant keratinized gingiva (in mm), pink aesthetic scores (PES), probing depths (in $\mathrm{mm}$ ), bleeding on probing (BOP), peri-implant bone loss (in $\mathrm{mm}$ ) and the presence of peri-implant osteolysis. Probing depths were measured with a blunt periodontal probe at six sites (mesio-buccal, buccal, disto-buccal, mesio-oral, oral, disto-oral). The width and thickness of keratinized peri-implant soft tissue was measured with a pointed calibrated probe at standardized measuring points around the implant. For the PES assessment, frontal photographs of implants with fixed restorations in place (44 
implants) were taken, including the antagonist/adjacent teeth for comparison. The photographs were composed into a presentation in random order. Three independent and experienced blinded investigators familiar with the PES scoring method reviewed all images on the same portable computer. The score was computed by adding the point score (from $0=$ =very bad to $2=$ =xcellent) for the seven items (mesial papilla, distal papilla, soft-tissue level, soft-tissue contour, alveolar process deficiency, soft-tissue colour and texture) for a maximum score of 14. Further, peri-implant bone loss was investigated by digitally recorded panoramic radiographs routinely taken after implant insertion and upon re-examination. Bone loss was estimated using radiological software appropriate for the x-ray system used. These examinations were used to determine the ability of the implant system to maintain implant stability, peri-implant health and peri-implant bone after a mean loading time of two years.

\section{Investigation parameters}

A. Implant survival

B. Width and thickness of peri-implant keratinized gingiva
C. Pink esthetic score (PES)

D. Probing depth

E. Bleeding on probing (BOP)

F. Peri-implant bone loss

G. Presence of peri-implant osteolysis

\section{Results}

\section{Clinical results}

Altogether, 50 implants were placed after the extraction of non-salvageable teeth: 31 implants were placed in the upper jaw and 19 implants in the lower jaw. Implant diameters were $3 \mathrm{~mm} \mathrm{(4}$ implants), $3.5 \mathrm{~mm}$ (34 implants) or $4.3 \mathrm{~mm}$ (12 implants). Implant lengths were $9 \mathrm{~mm}$ (1 implant), $11 \mathrm{~mm}$ (25 implants) or $13 \mathrm{~mm}(24$ implants). A total of ten implants, all in the upper jaw, were restored and loaded immediately, and the loading of 40 implants was delayed after a mean healing period of six months (four to seven months). Prosthetic restoration consisted of fixed prosthetics (44 implants) and removable prosthetics (six implants) see Table 1.

Table 1: I Participating patients and the number and site of the inserted implants (f: Female; m: Male; u. j.: Upper jaw; 1. j.: Lower jaw/ d. 1.: Delayed loading; i. 1.: Immediate loading/f. p.: Fixed prosthetics; r. p.: Removable prosthetics).

\begin{tabular}{|c|c|c|c|c|c|c|c|}
\hline Patient & $\begin{array}{c}\text { Gender } \\
(\mathrm{m} / \mathrm{f})\end{array}$ & Age (Years) & $\begin{array}{c}\text { Implant Localisation } \\
\text { (region) }\end{array}$ & $\begin{array}{l}\text { Implant Diameter } \\
(\mathrm{mm})\end{array}$ & $\begin{array}{c}\text { Implant } \\
\text { Length (mm) }\end{array}$ & $\begin{array}{l}\text { Loading Pro- } \\
\text { tocol }\end{array}$ & $\begin{array}{c}\text { Prosthetic Rehabil- } \\
\text { itation }\end{array}$ \\
\hline \multirow[t]{6}{*}{1} & $\mathrm{f}$ & 51 & 14 & 3,5 & 13 & d.l. & f.p. \\
\hline & & & 11 & 3,5 & 13 & d.l. & f.p. \\
\hline & & & 21 & 4,3 & 11 & d.l. & f.p. \\
\hline & & & 24 & 3,5 & 13 & d.l. & f.p. \\
\hline & & & 31 & 3 & 11 & d.l. & r.p. \\
\hline & & & 41 & 3 & 11 & d.l. & r.p. \\
\hline \multirow[t]{2}{*}{2} & $\mathrm{~m}$ & 74 & 21 & 3 & 11 & d.l. & f.p. \\
\hline & & & 23 & 4,3 & 13 & d.l. & f.p. \\
\hline \multirow[t]{2}{*}{3} & $\mathrm{~m}$ & 51 & 16 & 3,5 & 13 & d.l. & f.p. \\
\hline & & & 24 & 3,5 & 13 & d.l. & f.p. \\
\hline 4 & $\mathrm{f}$ & 54 & 25 & 3,5 & 13 & d.l. & f.p. \\
\hline \multirow[t]{2}{*}{5} & $\mathrm{~m}$ & 69 & 14 & 3,5 & 11 & d.l. & f.p. \\
\hline & & & 15 & 4,3 & 13 & d.l. & f.p. \\
\hline 6 & $\mathrm{~m}$ & 59 & 12 & 4,3 & 13 & d.l. & f.p. \\
\hline 7 & $\mathrm{f}$ & 62 & 46 & 4,3 & 11 & d.l. & f.p. \\
\hline \multirow[t]{2}{*}{8} & $\mathrm{~m}$ & 58 & 46 & 4,3 & 11 & d.l. & f.p. \\
\hline & & & 26 & 4,3 & 11 & d.l. & f.p. \\
\hline 9 & $\mathrm{f}$ & 65 & 12 & 3,5 & 13 & d.l. & f.p. \\
\hline \multirow[t]{4}{*}{10} & $\mathrm{f}$ & 66 & 15 & 3,5 & 11 & i.l. & f.p. \\
\hline & & & 14 & 3,5 & 13 & i.l. & f.p. \\
\hline & & & 13 & 3,5 & 13 & i.l. & f.p. \\
\hline & & & 23 & 3,5 & 13 & i.l. & f.p. \\
\hline
\end{tabular}




\begin{tabular}{|c|c|c|c|c|c|c|c|}
\hline & & & 24 & 3,5 & 13 & i.l. & f.p. \\
\hline & & & 25 & 3,5 & 11 & i.l. & f.p. \\
\hline 11 & $\mathrm{~m}$ & 69 & 42 & 3,5 & 13 & d.l. & f.p. \\
\hline \multirow[t]{2}{*}{12} & $\mathrm{~m}$ & 51 & 34 & 3,5 & 11 & d.l. & f.p. \\
\hline & & & 46 & 4,3 & 11 & d.l. & f.p. \\
\hline 13 & $\mathrm{f}$ & 64 & 15 & 3,5 & 13 & d.l. & f.p. \\
\hline 14 & $\mathrm{f}$ & 71 & 44 & 3,5 & 11 & d.l. & f.p. \\
\hline 15 & $\mathrm{f}$ & 69 & 36 & 3,5 & 11 & d.l. & f.p. \\
\hline \multirow[t]{3}{*}{16} & $\mathrm{~m}$ & 54 & 22 & 3,5 & 13 & d.l. & f.p. \\
\hline & & & 37 & 4,3 & 9 & d.l. & f.p. \\
\hline & & & 47 & 4,3 & 11 & d.l. & f.p. \\
\hline \multirow[t]{2}{*}{17} & $\mathrm{f}$ & 47 & 13 & 3,5 & 11 & d.l. & f.p. \\
\hline & & & 15 & 3,5 & 11 & d.l. & f.p. \\
\hline 18 & $\mathrm{f}$ & 69 & 41 & 3 & 11 & d.l. & f.p. \\
\hline \multirow[t]{5}{*}{19} & $\mathrm{f}$ & 58 & 17 & 3,5 & 11 & d.l. & f.p. \\
\hline & & & 21 & 3,5 & 13 & i.l. & f.p. \\
\hline & & & 22 & 3,5 & 13 & i.l. & f.p. \\
\hline & & & 23 & 3,5 & 13 & i.l. & f.p. \\
\hline & & & 24 & 3,5 & 11 & i.l. & f.p. \\
\hline \multirow[t]{5}{*}{20} & $\mathrm{~m}$ & 56 & 17 & 4,3 & 11 & d.l. & f.p. \\
\hline & & & 27 & 3,5 & 11 & d.l. & f.p. \\
\hline & & & 37 & 4,3 & 11 & d.l. & f.p. \\
\hline & & & 46 & 3,5 & 11 & d.l. & f.p. \\
\hline & & & 47 & 3,5 & 11 & d.l. & f.p. \\
\hline \multirow[t]{4}{*}{21} & $\mathrm{~m}$ & 64 & 41 & 3,5 & 13 & d.l. & r.p. \\
\hline & & & 43 & 3,5 & 13 & d.l. & r.p. \\
\hline & & & 31 & 3,5 & 13 & d.l. & r.p. \\
\hline & & & 33 & 3,5 & 13 & d.l. & r.p. \\
\hline \multirow[t]{2}{*}{ Total: 21} & \multirow[t]{2}{*}{$11^{*} \mathrm{f} ; 10^{*} \mathrm{~m}$} & \multirow[t]{2}{*}{ Mean: 61} & total: 50 & \multicolumn{2}{|c|}{$\begin{array}{c}34 * 3,5 / 12 * 4,3 \\
1 * 9 / 25 * 11 /\end{array}$} & \multirow[t]{2}{*}{$10 *$ i. l. $/ 40 *$ d. l. } & \multirow[t]{2}{*}{$44^{*}$ f. p. $/ 6^{*}$ r. p } \\
\hline & & & $31 *$ u. j/19*l. j. & & & & \\
\hline
\end{tabular}

At the two year follow up investigation, all implants were in situ and suitable for prosthetic rehabilitation, which corresponded to an overall survival rate of 100 percent. It must be mentioned that prosthetic complications, such as screw fracture, abutment fracture or loss of retention were not present in any of the implants during the two year window. An analysis of the width and thickness of the peri-implant keratinized gingiva was performed to determine a potential correlation between keratinized peri-implant gingiva, a potential inflammatory response and peri-implant bone loss, and peri-implant osteolysis. A band of keratinized gingiva of at least $1 \mathrm{~mm}$ in width and thickness was found around all implants. The mean width of the peri-implant keratinized gingiva was $2.04 \mathrm{~mm}$ (upper jaw: $2.19 \mathrm{~mm}$; lower jaw: $1.79 \mathrm{~mm}$ ), and the mean thickness of the peri-implant keratinized gingiva was $1.66 \mathrm{~mm}$ (upper jaw:
$1.77 \mathrm{~mm}$; lower jaw: $1.47 \mathrm{~mm}$ ). No significant correlation between the width and thickness of the peri-implant gingiva and probing depths, BOP and marginal bone loss could be detected.

Probing depths and BOP were assessed with a blunt periodontal probe to describe the condition of the peri-implant soft tissue and to determine potential inflammation. The mean probing depth, measured at six sites per implant, was $2.25 \mathrm{~mm}$. BOP was present on 17 of the 50 implants (corresponding to 34.0 percent). A distinct correlation between the accumulation of plaque and increased probing depth could be observed, as most implants with BOP presented probing depths of at least $3 \mathrm{~mm}$. The aesthetic appearance of the immediate placed implants was evaluated by the PES. The measured items were mesial papilla, distal papilla, soft tissue level, 
soft tissue contour, alveolar process deficiency, soft tissue colour and texture, with a score of 0 to 2 (from $0=$ very bad to $2=$ excellent). The mean evaluated PES achieved for the immediate placed implants was 10.91 (ranging from 9 to 13; upper jaw: 11.03; lower jaw: 10.62), from a maximum score of 14 .

\section{Radiological results}

Radiological images (Yoshida, Japan), recorded after implant placement to control the implant position and for the regular fol- low up investigation after two years of loading, were examined to determine peri-implant bone levels and detect any peri-implant osteolysis. A stable peri-implant bone level reaching the implant shoulder was present around all 50 implants. Further, no osseous peri-implant defect was obvious in the groups. The mean bone loss calculated digitally was $0.83 \mathrm{~mm}$ (upper jaw: $0.85 \mathrm{~mm}$; lower jaw: $0.8 \mathrm{~mm}$ ), ranging from 0 to $1.7 \mathrm{~mm}$. Table 2 gives an overview on the results of the clinical and radiological two year follow up.

Table 2: I Results from the clinical and radiological two-year follow-up investigation (mb: Mesio buccal; b: Buccal; db: Disto buccal; mo: Mesio oral; o: Oral; do: Disto oral; +: Present; -: Absent; f. p.: Fixed prosthetics; r. p.: Removable prosthetics; u. j.: Upper jaw; 1. j.: Lower jaw).

\begin{tabular}{|c|c|c|c|c|c|c|c|c|}
\hline S.No. & $\begin{array}{l}\text { Patient Implant } \\
\text { Localisation } \\
\text { (Region) }\end{array}$ & $\begin{array}{c}\text { Implant } \\
\text { Loss (+/-) }\end{array}$ & $\begin{array}{c}\text { Buccal Width } \\
\text { of Keratinized } \\
\text { Peri-Implant } \\
\text { Gingiva (mm) }\end{array}$ & $\begin{array}{c}\text { Buccal Thickness } \\
\text { of Keratinized } \\
\text { Peri-Implant } \\
\text { Gingiva (mm) }\end{array}$ & $\begin{array}{c}\text { Pink } \\
\text { Esthetic } \\
\text { Score } \\
\text { (Pes) }\end{array}$ & $\begin{array}{l}\text { Probing Depth } \\
\text { (Mm) At Six Sites } \\
\text { (Mb, B, Db, Mo, } \\
\text { O, Do) }\end{array}$ & $\begin{array}{l}\text { Bleeding } \\
\text { on Probing } \\
\text { (Bop) (+/-) }\end{array}$ & $\begin{array}{l}\text { Peri-Implant } \\
\text { Bone Loss } \\
(\mathrm{mm}) \text { Mesial } \\
\text { and Distal }\end{array}$ \\
\hline 1 & 14 & - & 2 & 3 & 11 & $4,3,2,3,3,3$ & + & 0.7 \\
\hline & 11 & - & 3 & 2 & 12 & $3,3,2,2,2,3$ & - & 0.5 \\
\hline & 21 & - & 3 & 2 & 12 & $3,3,2,2,2,3$ & - & 0.6 \\
\hline & 24 & - & 2 & 3 & 10 & $2,2,3,3,3,2$ & - & 0.8 \\
\hline & 31 & - & 2 & 1 & r.p. & $2,2,1,1,1,2$ & - & 1.1 \\
\hline & 41 & - & 2 & 1 & r.p. & $2,2,1,1,1,2$ & - & 0.4 \\
\hline 2 & 21 & - & 2 & 2 & 12 & $4,2,3,2,2,3$ & + & 1.1 \\
\hline & 23 & - & 3 & 3 & 11 & $3,2,3,3,3,2$ & - & 0.5 \\
\hline 3 & 16 & - & 1 & 1 & 9 & $3,1,3,3,1,3$ & - & 0.7 \\
\hline & 24 & - & 2 & 1 & 11 & $2,1,2,2,1,2$ & - & 0.8 \\
\hline 4 & 25 & - & 2 & 1 & 11 & $3,1,2,2,1,2$ & - & 0.7 \\
\hline 5 & 14 & - & 2 & 2 & 11 & $4,2,2,2,2,3$ & + & 0.6 \\
\hline & 15 & - & 1 & 2 & 10 & $3,2,2,3,1,4$ & + & 1.4 \\
\hline
\end{tabular}




\begin{tabular}{|c|c|c|c|c|c|c|c|c|}
\hline 6 & 12 & - & 3 & 2 & 12 & $4,2,3,2,2,3$ & + & 1.1 \\
\hline 7 & 46 & - & 1 & 1 & 9 & $2,1,3,2,1,3$ & - & 0.8 \\
\hline \multirow[t]{2}{*}{8} & 46 & - & 2 & 2 & 10 & $4,2,3,2,2,3$ & - & 0.6 \\
\hline & 26 & - & 3 & 2 & 11 & $3,3,2,2,2,3$ & - & 0.8 \\
\hline 9 & 12 & - & 2 & 1 & 12 & $3,1,2,3,1,3$ & + & 1.2 \\
\hline \multirow[t]{6}{*}{10} & 15 & - & 2 & 1 & 11 & $3,1,2,3,1,4$ & + & 0.8 \\
\hline & 14 & - & 2 & 1 & 12 & $3,2,1,1,2,2$ & - & 1.2 \\
\hline & 13 & - & 3 & 2 & 12 & $3,3,2,2,3,2$ & - & 1.4 \\
\hline & 23 & - & 3 & 2 & 12 & $3,3,2,2,2,3$ & - & 1.1 \\
\hline & 24 & - & 2 & 2 & 12 & $2,1,2,1,1,2$ & - & 0.6 \\
\hline & 25 & - & 1 & 1 & 11 & $3,2,2,3,1,2$ & - & 0.5 \\
\hline 11 & 42 & - & 2 & 1 & 10 & $3,1,3,4,1,3$ & + & 1.2 \\
\hline \multirow[t]{2}{*}{12} & 34 & - & 2 & 2 & 11 & $2,2,3,2,1,3$ & - & 1.2 \\
\hline & 46 & - & 1 & 1 & 10 & $3,2,2,2,1,3$ & - & 0.8 \\
\hline 13 & 15 & - & 2 & 2 & 11 & $3,2,2,2,1,3$ & - & 0 \\
\hline 14 & 44 & - & 1 & 2 & 13 & $4,2,1,2,2,3$ & + & 0.4 \\
\hline 15 & 35 & - & 2 & 1 & 11 & $3,1,2,1,1,3$ & - & 1.2 \\
\hline \multirow[t]{3}{*}{16} & 22 & - & 2 & 2 & 13 & $2,2,3,2,1,3$ & + & 1.4 \\
\hline & 37 & - & 1 & 2 & 11 & $2,1,2,2,2,1$ & - & 0 \\
\hline & 47 & - & 1 & 3 & 12 & $2,1,3,3,2,2$ & - & 0.7 \\
\hline \multirow[t]{2}{*}{17} & 13 & - & 3 & 2 & 11 & $4,2,3,2,2,3$ & + & 1 \\
\hline & 15 & - & 2 & 2 & 11 & $2,1,2,3,2,2$ & - & 0.8 \\
\hline
\end{tabular}




\begin{tabular}{|c|c|c|c|c|c|c|c|c|}
\hline 18 & 41 & - & 3 & 2 & 10 & $4,2,3,2,2,3$ & + & 0 \\
\hline \multirow[t]{5}{*}{19} & 17 & - & 1 & 2 & 9 & $3,2,3,2,2,3$ & - & 0.8 \\
\hline & 21 & - & 2 & 2 & 10 & $2,1,3,2,2,2$ & - & 1.2 \\
\hline & 22 & - & 2 & 2 & 11 & $2,1,3,4,2,2$ & + & 0.6 \\
\hline & 23 & - & 3 & 2 & 11 & $3,3,2,2,2,3$ & + & 0.4 \\
\hline & 24 & - & 2 & 1 & 11 & $2,1,2,3,1,2$ & - & 0.6 \\
\hline \multirow[t]{5}{*}{20} & 17 & - & 2 & 1 & 10 & $4,1,2,3,1,3$ & - & 1 \\
\hline & 27 & - & 3 & 1 & 9 & $3,2,3,2,1,3$ & - & 1.6 \\
\hline & 37 & - & 1 & 1 & 10 & $2,1,3,2,1,2$ & - & 0.9 \\
\hline & 46 & - & 1 & 1 & 11 & $3,2,2,1,1,2$ & - & 1.7 \\
\hline & 47 & - & 1 & 1 & 10 & $4,2,2,3,3,3$ & + & 1.2 \\
\hline \multirow[t]{4}{*}{21} & 41 & - & 3 & 1 & r.p. & $3,1,2,1,1,3$ & - & 0.6 \\
\hline & 43 & - & 2 & 2 & r.p. & $3,2,2,4,2,2$ & + & 0.8 \\
\hline & 31 & - & 3 & 1 & r.p. & $3,2,2,3,1,3$ & - & 1.3 \\
\hline & 33 & - & 3 & 2 & r.p. & $3,1,3,2,2,3$ & + & 0.8 \\
\hline \multicolumn{9}{|c|}{ Total:21 } \\
\hline \multirow{4}{*}{1} & Total: 50 & Total: 0 & Mean Total & Mean Total & Mean Total & Mean Total & Mean Total & Mean Total \\
\hline & $31 *$ u. j. & & $2.04 \mathrm{~mm}$ & $1.66 \mathrm{~mm}$ & 10.91 & $2.25 \mathrm{~mm}$ & $34.00 \%$ & $0.83 \mathrm{~mm}$ \\
\hline & & & u. j.: $2.19 \mathrm{~mm}$ & u.j.: $1.77 \mathrm{~mm}$ & u. j.: 11.03 & u. j.: $2.31 \mathrm{~mm}$ & u. j.: $35.5 \%$ & u. j.: $0.85 \mathrm{~mm}$ \\
\hline & $19 *$ l. j. & & l. j.: $1.79 \mathrm{~mm}$ & l. j.:1.47 mm & l. j.: 10.62 & l. j.: $2.14 \mathrm{~mm}$ & l. j.: $31.6 \%$ & l. j.: $0.8 \mathrm{~mm}$ \\
\hline
\end{tabular}

\section{Discussion}

This retrospective study reports on a two year follow up investigation of a newly developed implant system on immediate placement in fresh extraction sockets. Implants were analyzed regarding implant stability and peri-implant soft and hard tissue health using established methods [36,37]. After a mean loading period of two years, all 50 implants were still in situ and usable for prosthetic rehabilitation. The peri-implant tissue presented healthy and stable in all cases, without any signs of acute infection or peri-implantitis. Probing depths and BOP around the implants served as markers for peri-implant soft tissue health. The values for the probing depths 
(mean: $2.25 \mathrm{~mm}$ ) and BOP (mean: 34 percent) were in accordance with the values found in the literature [38,39]. When comparing the probing depths and BOP on dental implants and natural teeth, it must always be remembered that the anatomy and morphology of the peri-implant soft tissue structure is different from that of natural teeth, as dental implants do not possess a compact barrier against penetration from the oral cavity and they act more like a cuff like barrier [40]. Further, the peri-implant soft tissue contains fewer blood vessels $[41,42]$ and cells, but more collagen, which leads to a greater susceptibility to plaque induced inflammation and bleeding $[40,43]$. Investigation of the mean peri-implant bone loss after two years of loading revealed $0.83 \mathrm{~mm}$ (upper jaw: $0.85 \mathrm{~mm}$; lower jaw: $0.8 \mathrm{~mm}$ ). The peri-implant bone around all 50 implants reached the implant shoulder and showed no signs of acute peri-implant osteolysis or peri-implantitis.
Immediate implant placement is a reliable and promising technique to replace teeth not worth preserving, at the same time reducing the treatment time (Figure 2-4). Immediate implant placement, especially in the aesthetic zone, can help preserve the fragile buccal bone, which is important for an aesthetically sufficient result. A further approach to fast oral rehabilitation is immediate loading of the implant, which requires high primary implant stability. The prerequisites for both immediate placement and immediate loading of dental implants are an intact extraction site and an awareness of any acute inflammation present $[26,44,45]$. Numerous studies have examined the impact of immediate implant placement on implant failure, the occurrence of postoperative infection and the magnitude of marginal bone loss $[13,46]$. In clinical study evaluating long term bone stability up to twelve years by radiographic analysis, it was shown that 312 implants with an anodic oxidized surface presented a mean bone loss of $0.4 \mathrm{~mm}( \pm 0.80 \mathrm{~mm})$.
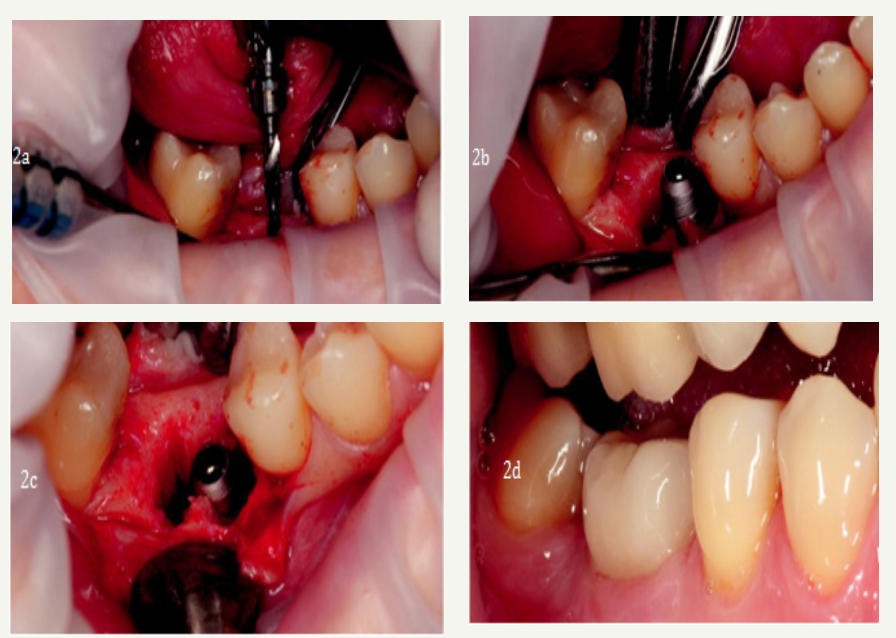

Figure 2: Clinical image of patient 15. A dental implant was inserted at site 36 and restored with fixed prosthetics.

a: Implant drilling after extraction of tooth 36

b and c: Implant insertion

d: Two-year follow-up
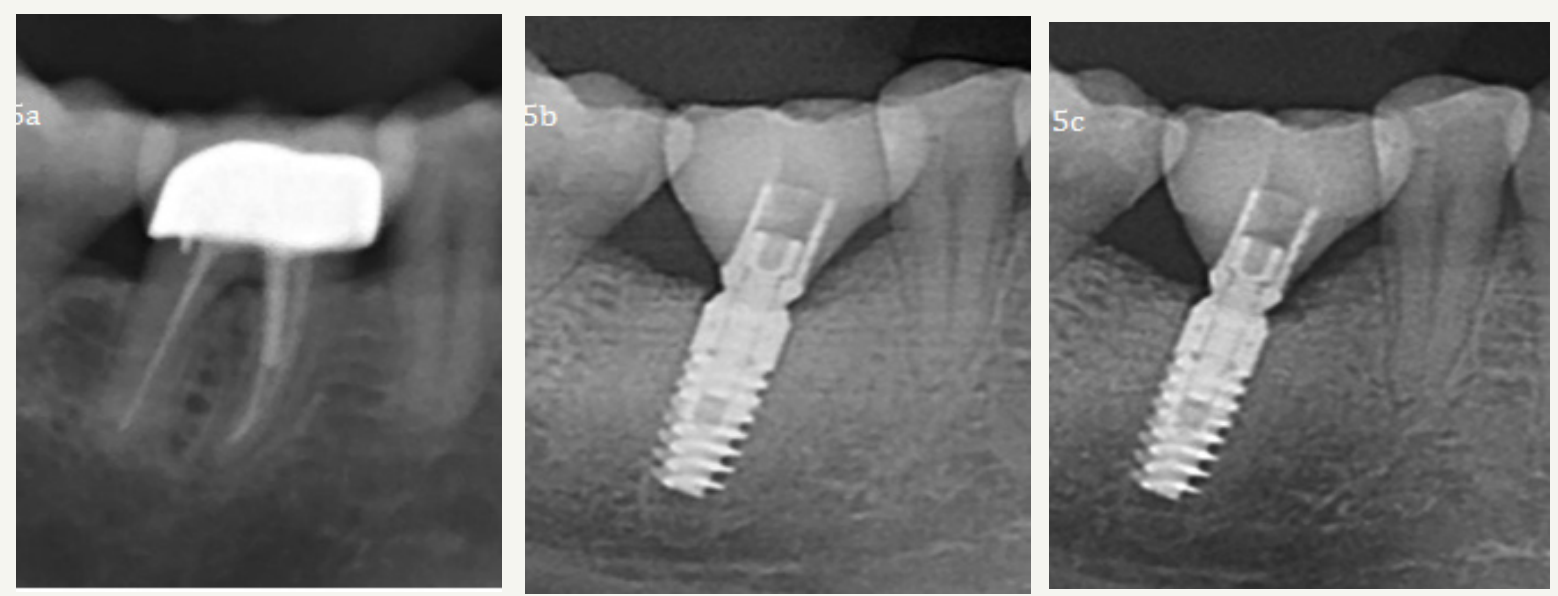

Figure 3: Radiographic images of patient 15.

a: X-ray image of tooth 36 , which was not salvageable due to persisting pain prior to extraction

b: X-ray image of implant 36 immediately after prosthetic rehabilitation. The bone level reaches the implant shoulder

c: X-ray image of implant 36 at the 2-year follow up. The peri-implant bone level is stable and no peri-implant osteolysis was detected 

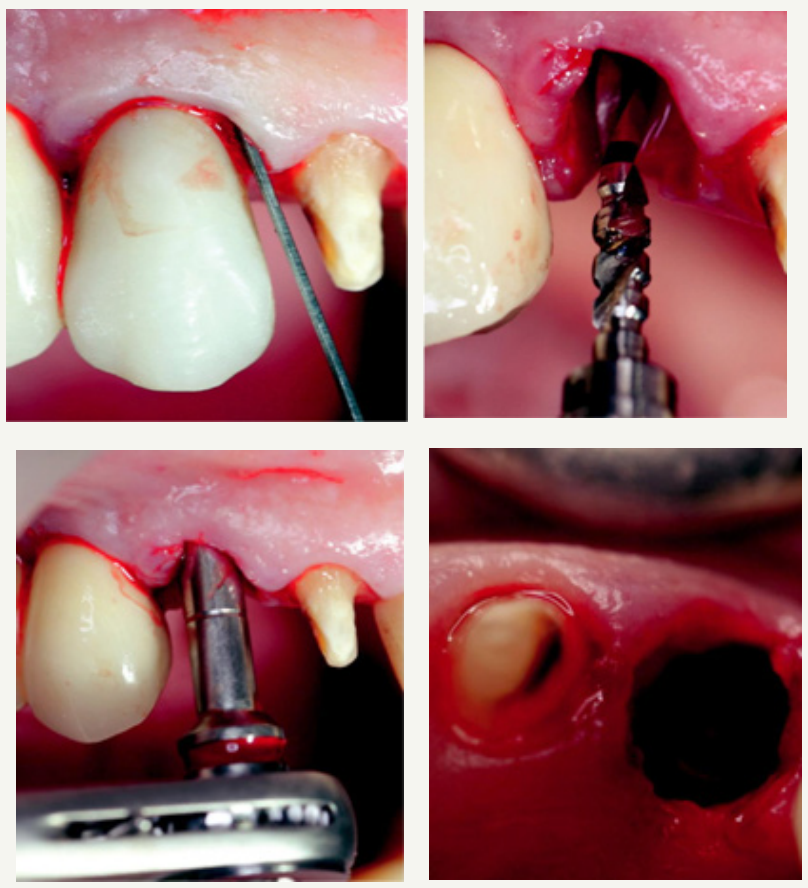

Figure 4: Clinical image of patient 17. Dental implant inserted at site 13 and restored with fixed prosthetics.

a: Tooth 13 before extraction

b: Implant drilling after extraction of tooth 13

c: Implant insertion

d: After slightly sub-crestal implant insertion

In a systematic review, Chrcanovic et al. [13] examined whether the immediate placement of dental implants increased the rates of implant failure, postoperative infection or marginal bone loss. This meta analysis of a high number of reviewed publications (73) comparing implants in fresh extraction sockets to implants inserted in healed sites revealed no significant difference in terms of failed implants (4.00 per cent in fresh extraction sites, 3.09 percent in healed extraction sites), postoperative infection or marginal bone loss.

The newly developed implant system investigated in the present retrospective study features bone-level implants with a bevelled shoulder, which allows for sub-crestal insertion (Figure 4). It has a thread design that is different in the crestal and apical portions of the implant, making for high primary stability. The implant surface is grit-blasted and acid-etched, which, in combination with the thread design, achieves a large surface. The implant/abutment connection is a Morse-locking conical connection with platform switching and an indexing hex, which aims to prevent peri-implant bone loss. Starting with the original research in implant dentistry by Brånemark [9], it had been obvious that the most important factor for the longevity of dental implants is osseointegration. Previous research studies have shown that primary stability in combination with a large surface is predictors for osseointegration [47]. Primary stability of the implant within the implant bed was found to be achieved by a progressive thread design and a combination of macro and microgrooves on the implant [48]. Further modifications of the implant surface seemed to increase the rate of osteoblast accretion, which, in combination with primary stability, is a prerequisite for sufficient and stable osseointegration [49]. Especially in implants inserted immediately after tooth extraction, achieving primary stability is of paramount importance, as the extraction site determines the local bone amount and therefore the bone to implant contact [49]. Also important in the design of dental implants is the implant/ abutment connection. Multiple in vitro and clinical investigations have shown that a conical connection in combination with internal platform switching reduces micro movements and thus bacterial contamination by propelling sulcus fluid, which results in marginal bone loss $[34,35,50]$. With its combination of characteristics, the investigated newly designed implant system seems to meet the requirements for a successful dental implant system. The results from the two year follow up have demonstrated that immediate implant placement using the right implant system can, in certain cases, be a reliable and long term stable approach to replacing missing teeth and restoring articulation and mastication. In addition to technical and surgical considerations, it has to be mentioned that-especially in immediate placement-strict and cautious case selection is necessary to achieve predictable outcomes.

\section{Conclusion}

The present retrospective analysis reports the results of a two-year clinical and radiological follow up in 21 patients. A total of 50 implants of a newly developed implant system were placed immediately after extraction in the upper and lower jaw and restored immediately or delayed. The focus of the follow up was on peri-implant hard and soft tissue health, by analysing the buccal 
width and thickness of the keratinized peri-implant gingiva, probing depths, presence of bleeding on probing and marginal bone loss. Further, the aesthetic appearance of the implants and the implant retained prosthetics were determined using the pink esthetic score. All implants survived the two year follow up without any signs of peri-implantitis or acute peri-implant infection (Figure $2 \& 3$ ). All implants presented a sufficient amount of peri-implant keratinized soft tissue, low probing depths (mean: $2.25 \mathrm{~mm}$ ), and BOP (34 percent) (Figure 4). The peri-implant bone level was stable, with a mean bone loss after two years of loading of $0.83 \mathrm{~mm}$. Regarding the results of the two year follow up examination, it can be concluded that the implant system examined affords a high rate of implant stability and adequate peri-implant hard and soft tissue health. Immediate implant placement using a suitable implant system can, in certain cases, be a reliable, long term stable as well as time and cost effective strategy to replace teeth not worth preserving.

\section{References}

1. Albrektsson T, Dahl E, Enbom L, Engevall S, Engquist B, et al. (1988) Osseointegrated oral implants. A Swedish multicenter study of 8139 consecutively inserted nobelpharma implants. J Periodontol 59(5): 287 296.

2. Spiekermann H, Jansen VK, Richter EJ (1995) A 10-year follow-up study of IMZ and TPS implants in the edentulous mandible using bar-retained overdentures. Int J Oral Maxillofac Implants 10(2): 231-243.

3. Nevins M, Langer B (1993) The successful application of osseointegrated implants to the posterior jaw: a long-term retrospective study. Int J Oral Maxillofac Implants 8(4): 428-432.

4. Henry PJ, Laney WR, Jemt T, Harris D, Krogh PH, et al. (1996) Osseointegrated implants for single-tooth replacement: a prospective 5-year multicenter study. Int J Oral Maxillofac Implants 11(4): 450-455.

5. Schmitt A, Zarb GA (1993) The longitudinal clinical effectiveness of osseointegrated dental implants for single-tooth replacement. Int J Prosthodont 6(2): 197-202.

6. Fugazzotto PA, Gulbransen HJ, Wheeler SL, Lindsay JA (1993) The use of IMZ osseointegrated implants in partially and completely edentulous patients: success and failure rates of 2,023 implant cylinders up to 60+ months in function. Int J Oral Maxillofac Implants 8(6): 617-621.

7. Misch CE (1990) Density of bone: effect on treatment plans, surgical approach, healing, and progressive boen loading. Int J Oral Implantol 6(2): 23-31.

8. Albrektsson T, Lekholm U (1989) Osseointegration: current state of the art. Dent Clin North Am 33 (4): 537-554.

9. Adell R, Lekholm U, Brånemark PI (1985) Surgical procedures. In: Brånemark PI, Zarb G, Albrektsson T (Eds.), Tissue Integrated Prostheses: Surgical Procedures, Quintessence Publishing Co, Chicago, USA, pp. 223-225.

10. Kohal RJ, LaRosa M, Patrick D, Hürzeler MB, Caffesse RG (1999) Clinical and histologic evaluation of submerged and nonsubmerged hydroxyapatite-coated im-plants: a preliminary study in dogs. Int J Oral Maxillofac Implants 14(6): 824-834.

11. Evian CI, Kessler L, Axler J (1997) One-stage surgery with a nonsubmerged implant system. Compend Contin Educ Dent 18(11): 1091-1094, 1096-1098.

12. Ericsson I, Nilner K, Klinge B, Glantz PO (1996) Radio-graphical and histological characteristics of submerged and nonsubmerged titanium implants. An experimental study in the Labrador dog. Clin Oral Implants Res 7(1): 20-26.

13. Chrcanovic BR, Albrektsson T, Wennerberg A (2015) Dental implants inserted in fresh extraction sockets versus healed sites: a systematic review and meta-analysis. J Dent 43(1): 16-41.

14. Weiss CM, Weiss A, Rosenlicht J (2001) Root form implants. Treatment of total mandibular edentulism diagnosed for an overdenture. In: Weiss CM, Weiss A, (Eds.), Principles and Practice of Implant Dentistry, Mosby, St Louis, USA, pp. 147-168.

15. Fickl S, Zuhr O, Wachtel H, Stappert CF, Stein JM, et al. (2008) Dimensional changes of the alveolar ridge contour after different socket preservation techniques. J Clin Peri-odontol 35(10): 906-913.

16. Vignoletti F, Matesanz P, Rodrigo D, Figuero E, Martin C, et al. (2012) Surgical protocols for ridge preservation after tooth extraction. A systematic review. Clin Oral Implants Res 23(5): 22-38.

17. Lekovic V, Camargo PM, Klokkevold PR, Weinlaender M, Kenney EB, et al. (1998) Preservation of alveolar bone in extraction sockets using bioabsorbable membranes. J Periodontol 69(9): 1044-1049.

18. Becker W, Becker B, Polizzi G, Bergstrom C (1994) Autogenous bone grafting of defects adjacent to implants placed into immediate extraction sockets in patients: a prospective study. Int J Oral Maxillofac Implants 9(4): 389-396.

19. Artzi Z, Tal H, Dayan D (2001) Porous bovine bone mineral in healing of human extraction sockets: 2. Histo-chemical observations at 9 months. J Periodontol 72(2): 152-159.

20. Iasella JM, Greenwell H, Miller RL, Hill M, Drisko C (2003) Ridge preservation with freeze-dried bone allograft and a collagen membrane compared to extraction alone for implant site development: a clinical and histologic study in humans. J Periodontol 74(7): 990-999.

21. Araújo MG, Lindhe J (2005) Dimensional ridge alterations following tooth extraction. An experimental study in the dog. J Clin Periodontol 32(2): 212-218.

22. Evans CD, Chen ST (2008) Esthetic outcomes of immediate implant placements. Clin Oral Implants Res 19(1): 73-80.

23. Chen ST, Darby IB, Reynolds EC, Clement JG (2009) immediate implant placement postextraction without flap elevation. J Periodontol 80(1): 163-172.

24. Lang NP, Pun L, Lau KY, Li KY, Wong MC (2012) A systematic review on survival and success rates of implants placed immediately into fresh extraction sockets after at least 1 year. Clin Oral Implants Res 23(5): 3966.

25. Pagni G, Pellegrini G, Giannobile WV, Rasperini G (2012) Postextraction alveolar ridge preservation: biological basis and treatments. Int J Dent 2012: 151030.

26. Tavarez RR, Calixto AM, Maia Filho EM, Bandeca MC, Firoozmand LM, et al. (2014) Atraumatic extraction, implant placement and immediate provisionalization. J Contemp Dent Pract 15(4): 513-517.

27. Misch CE (1999) Implant design considerations for the posterior regions of the mouth. Implant Dent 8(4): 376-386.

28. Binon PP (2000) Implants and components: entering the new millennium. Int J Oral Maxillofac Implants 15(1): 76-94.

29. Trisi P, Rao W, Rebaudi A (1999) A histometric comparison of smooth and rough titanium implants in human low-density jawbone. Int J Oral Maxillofac Implants 14(5): 689-698.

30. Steigenga JT, Shammari KF, Nociti FH, Misch CE, Wang HL (2003) Dental implant design and its relationship to long-term implant success. Implant Dent 12(4): 306-317.

31. Niznick G (2000) Achieving Osseointegration in soft bone: The search for improved results. Oral Health 90: 27-32.

32. O'Sullivan D, Sennerby L, Meredith N (2000) Measurements comparing the initial stability of five designs of dental implants: a human cadaver study. Clin Implant Dent Relat Res 2(2): 85-92. 
33. Sykaras N, Iacopino AM, Marker VA, Triplett RG, Woody RD (2000) Implant materials, designs, and surface topographies: their effect on osseointegration. A literature review. Int J Oral Maxillofac Implants 15(5): 675-690.

34. Canullo L, Penarrocha OD, Soldini C, Mazzocco F, Penarrocha M (2015) Microbiological assessment of the implant-abutment interface in different connections: cross-sectional study after 5 years of functional loading. Clin Oral Implants Res 26(4): 426-434.

35. Pozzi A, Tallarico M, Moy PK (2014) Three-year post-loading results of a randomised, con-trolled, split-mouth trial comparing implants with different prosthetic interfaces and design in partially posterior edentulous mandibles. Eur J Oral Implantol 7(1): 47-61.

36. Ghanaati S, Lorenz J, Obreja K, Choukroun J, Landes C, et al. (2014) Nanocrystalline hydroxyl apatite-based material already contributes to implant stability after 3 months: a clinical and radiologic 3-year followup investigation. J Oral Implantol 40(1): 103-109.

37. Ghanaati S, Barbeck M, Lorenz J, Stuebinger S, Seitz O (2013) Synthetic bone substitute material comparable with xeno-geneic material for bone tissue regeneration in oral cancer patients: First and preliminary histological, histomorpho-metrical and clinical results. Ann Maxillofac Surg 3(2): 126-138.

38. Sailer I, Zembic A, Jung RE, Siegenthaler D, Holderegger C (2009) Randomized controlled clinical trial of customized zirconia and titanium implant abutments for canine and posterior single-tooth implant reconstructions: preliminary results at 1 year of function. Clinical Oral Implants Research 20(3): 219-225.

39. Brägger U, Bürgin WB, Hämmerle CH, Lang NP (1997) Associations between clinical parameters assessed around implants and teeth Clinical Oral Implants Research 8(5): 412-421.

40. Berglundh T, Lindhe J, Ericsson I, Marinello CP, Liljenberg B, et al. (1991) The soft tissue barrier at implants and teeth. Clinical Oral Implants Research 2(2): 81-90.
41. Berglundh T, Lindhe J, Jonsson K, Ericsson I (1994) The topography of the vascular systems in the periodontal and peri-implant tissues in the dog. Journal of Clinical Periodontology 21(3): 189-193.

42. Moon IS, Berglundh T, Abrahamsson I, Linder E, Lindhe J (1999) The barrier between the keratinized mucosa and the dental implant. An experimental study in the dog. Journal of Clinical Periodontology 26(10): 658-663.

43. Lindhe J, Berglundh T (1998) The interface between the mucosa and the implant. Periodontology 2000 17: 47-54.

44. Rieder D, Eggert J, Krafft T, Weber HP, Wichmann MG (2014) Impact of placement and restoration timing on single-implant esthetic outcome-a randomized clinical trial. Clin Oral Implants Res 27(2): e80-e86.

45. Romanos GE, Aydin E, Locher K, Nentwig GH (2014): Immediate vs. delayed loading in the posterior mandible: a split-mouth study with up to 15 years of follow-up. Clin Oral Implants Res 27(2): e74-e79.

46. Wagenberg B, Froum SJ (2014) Long-Term Bone Stability around 312 Rough-Surfaced Immediately Placed Implants with 2-12-Year Follow-Up. Clin Implant Dent Relat Res 17(4): 658-666.

47. Javed F, Ahmed HB, Crespi R, Romanos GE (2013) Role of primary stability for successful osseointegration of dental implants: Factors of influence and evaluation. Interv Med Appl Sci 5(4): 162-167.

48. Calvo GJL, Gomez MG, Aguilar SA, Mate SVJE, Abboud M (2014) Bone remodeling at implants with different configurations and placed immediately at different depth into extraction sockets. Experimental study in dogs. Clin Oral Implants Res 26(5): 507-515.

49. Javed F, Almas K, Crespi R, Romanos GE (2011) Implant surface morphology and primary stability: is there a connection? Implant Dent 20(1): 40-46

50. Berberi A, Tehini G, Rifai K, Bou NEF, El ZN (2014) In vitro evaluation of leakage at implant-abutment connection of three implant systems having the same prosthetic interface using rhodamine B. Int J Dent 2014: 351263 .
Creative Commons Attribution 4.0

International License

For possible submissions Click Here

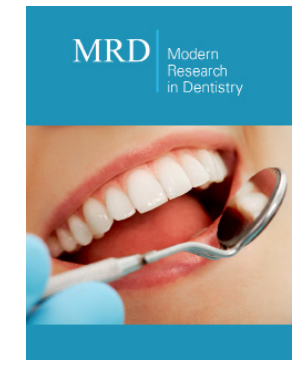

\section{Modern Research in Dentistry}

\section{Benefits of Publishing with us}

- High-level peer review and editorial services

- Freely accessible online immediately upon publication

- Authors retain the copyright to their work

- Licensing it under a Creative Commons license

- Visibility through different online platforms 